Aprovado em: 10/07/2017

\title{
DIÁRIOS VIRTUAIS DOS SERVOS DO SENHOR: A VIRILIDADE EM PERFIS DE PADRES MIDIÁTICOS NO INSTAGRAM
}

\section{VIRTUAL DIARIES OF THE LORD'S SERVANTS: VIRILITY IN MEDIA PRIESTS' PROFILES ON INSTAGRAM}

\author{
Diego Santos Vieira DE JESUS ${ }^{1}$
}

\section{Resumo:}

O objetivo é examinar as representações de virilidade nos perfis dos padres Marcelo Rossi e Fábio de Melo no Instagram. $\mathrm{O}$ argumento central sustenta que, apesar das diferenças em termos de linguagem e de abordagem de temas entre os dois, ambos os padres mobilizam a simplicidade e o apelo emocional, típicos da virilidade sacerdotal, ao reforçarem em seus posts a posição institucional de mediação entre Deus e os fiéis. Eles aliam a tais elementos fatores ligados à lógica do mercado e enfatizam simultaneamente aspectos de virilidade associados à beleza, à juventude, ao despojamento e até mesmo a um erotismo sutil, permitindo uma maior aproximação do sacerdote com seus seguidores.

Palavras-chave: Virilidade; Padres Midiáticos; Instagram.

\begin{abstract}
:
The purpose is to examine the representations of virility in the profiles of the priests Marcelo Rossi and Fábio de Melo on Instagram. The central argument holds that despite the differences in language and approach of themes between both priests, they mobilize the simplicity and the emotional appeal, typical of priest virility, by reinforcing in their posts the institutional position of mediation between God and the faithful people. However, they link to these elements factors linked to the logic of the market and emphasize at the same time aspects of virility associated with beauty, youth, detachment and even a subtle eroticism, which allows a closer approximation of the priest with his followers.
\end{abstract}

Keywords: Virility; Media Priests; Instagram.

\footnotetext{
${ }^{1}$ Doutor em Relações Internacionais pela PUC-Rio e docente e pesquisador do Programa de Mestrado Profissional em Gestão da Economia Criativa da ESPM-Rio. Membro do Laboratório de Cidades Criativas desta instituição/ dvieira@espm.br
} 


\section{miDiA \\ 数

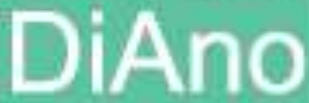

Introdução

A oferta de bens religiosos no Brasil é estruturada pela articulação de um conjunto de múltiplos setores culturais. A Igreja Católica e as evangélicas, por exemplo, operam com um grande complexo de redes de rádio e TV e atuam no mercado editorial. A indústria também comercializa milhões de CDs e DVDs com temática religiosa por ano. Produções cinematográficas católicas, evangélicas e espíritas se tornaram fenômenos de bilheteria em todo o país desde o início deste século. A disseminação desses bens ocorreu num contexto em que as Igrejas passaram a suprir demandas espirituais crescentes dos indivíduos, capturadas na cultura midiática. Representantes de religiões passaram a disseminar práticas que respondiam a tais demandas, de forma a estruturarem espaços midiáticos de cura e salvação mediante operações comerciais fundamentadas no marketing confessional. Inúmeras religiões passaram a se organizar e operar tomando como referências as lógicas e as operações midiáticas mercantilizadas (FAUSTO NETO, 2004, p.145-147).

O elo entre mídia e religião ilustra a influência dos dispositivos de comunicação no ambiente social, no qual os produtos midiáticos transformam-se em meios de interação, restabelecendo práticas sociais e propagando intencionalidades e discursividades (NASCIMENTO; GARCIA JÚNIOR, 2013). Hoje, a diversidade dos meios de comunicação tem viabilizado uma maior interação entre produtores e receptores do discurso religioso, o que veio estimulando a captação de fiéis pelas Igrejas. Os representantes religiosos veem a necessidade crescente de adaptação e de adequação de seus discursos às novas situações comunicacionais, em particular, o uso das redes sociais, e desenvolvem táticas para a maior aproximação com seu público. $\mathrm{Na}$ Igreja Católica, padres vêm gradualmente investindo em redes como o Facebook, o Twitter e o Instagram como maneiras de difundir e de popularizar o Catolicismo (MELO, 2015, p.71-74). Segundo Jorge Miklos, com a inserção do ciberespaço na lógica de consumo, o Catolicismo passou a se orientar cada vez mais por desejos consumistas e concorrer nas redes sociais com outras religiões pela adesão de fiéis (MIKLOS, 2012).

A mobilização intensiva de meios de comunicação para a divulgação da fé católica se fortaleceu com a aceitação de amplos públicos consumidores, em especial 
após a chegada, na década de 1970, da Renovação Carismática Católica (RCC), um movimento que surgiu de encontros organizados por estudantes e professores universitários e foi reconhecido pelo uso da música, gestos e danças como recursos para louvar a Deus, bem como pela revelação de religiosos cantores e pelo desenvolvimento de emissoras de rádio e de TV voltadas para a divulgação do movimento. Caracterizando-se a RCC no Brasil, é possível identificar uma forte relação entre a midiatização do catolicismo brasileiro e o crescimento e a aceitação da Renovação, num movimento que contribuiu para a diluição das linhas divisórias entre as produções midiáticas do catolicismo romano e as neopentecostais, cujo maior expoente é o bispo Edir Macedo (HARTMANN, 2006, p.4-5).

A disseminação das produções neopentecostais reitera o panorama diversificado em que a Igreja Católica está colocada e motiva novas interpretações acerca das alternativas disponíveis aos brasileiros em um momento de pluralismo religioso. Se a diversidade interna da Igreja coaduna-se com seu caráter universal capaz de abranger múltiplas expressões de uma mesma fé, ela também produz conflitos e animosidades internas, em especial as trazidas pela RCC, que carregam traços do ethos pentecostal e a atenção da hierarquia, observadora permanentemente de rupturas e de cismas (FERNANDES, 2013, p.30). Porém, como reação aos abalos à predominância da Igreja Católica no Brasil, o episcopado do país e o Vaticano ofereceram apoio a movimentos que buscaram restabelecer um "catolicismo emocional", como o promovido pela RCC. Tal catolicismo veio permeado de mecanismos que atendiam às multidões e se pautou em padres midiáticos que desenvolviam liturgias e shows em formato evangelizador, mobilizando a informalidade e as expressões de juventude em múltiplos canais religiosos ou não, como os ambientes virtuais de sites, blogs e as redes sociais, tais quais o Facebook, o Twitter e o Instagram (CARRANZA, 2011).

Dentre os padres que vieram ganhando destaque nas redes sociais com números crescentes de seguidores, cumpre destacar dois que se tornaram fenômenos nacionais em termos de atração de fieis com a venda de CDs e outros produtos culturais: Marcelo Rossi e Fábio de Melo, ambos ligados à RCC. Rossi se inspira em parâmetros celebrativos da RCC, cujos seguidores são os principais consumidores de seus produtos. Ele já utilizava músicas e coreografias em suas missas e conquistava considerável 
reconhecimento público nacional na década de 1990. Gravou CDs e DVDs que se tornaram fenômenos de vendas no Brasil e publicou livros hoje comercializados em mais de 30 países. Ele ainda reza missas e apresenta programas em emissoras de rádio e canais de TV (SILVA, 2015, p.11). Fábio de Melo, professor universitário, gravou CDs que mesclaram canções religiosas e músicas do cancioneiro popular e se tornaram recordistas de vendas no país. O padre também publicou livros de autoajuda e hoje apresenta um programa de TV, além de realizar shows pelo Brasil e aparecer frequentemente em programas de variedades e entrevistas (MELO, 2015, p.80). Cerca de uma década depois de Rossi ter ganhado tanta visibilidade na mídia brasileira, Fábio de Melo atraiu a atenção do público com um estilo peculiar, utilizando roupas de grifes famosas, praticando exercícios físicos e demonstrando uma preocupação adicional com a aparência física que rendeu a ele o rótulo de "padre-galã", caracterizado pela beleza, pela juventude e até mesmo por um sutil apelo erótico (NÓBREGA, 2009, p.1-2, 9).

Levando-se em conta a trajetória religiosa de ambos os padres, Fabio de Melo foi vinculado a uma congregação religiosa antes de se tornar um padre diocesano, ao passo que Rossi sempre o foi (MENDONÇA, 2013). Os dois adquiriram uma visibilidade que religiosos jamais tiveram na história recente do Brasil por conta da adaptação da linguagem religiosa para os novos meios de comunicação e da utilização das mídias eletrônicas, as quais permitiram o consumo de bens religiosos de maneira mais individual que coletiva pelos fieis (HARTMANN, 2006, p.11-12). O entretenimento personificado nesses padres ressalta a inserção de membros da Igreja em um contexto do que determinados autores colocariam como a "mercantilização da fé" na sociedade capitalista, em que novas ferramentas de linguagem são mobilizadas para se atingirem mais fiéis consumidores de produtos religiosos na era da informação (SILVA, 2015, p.12-13).

No que diz respeito ao discurso religioso, a utilização de redes sociais por esses religiosos trouxe uma alteração substantiva da forma como esse discurso se articula. Tradicionalmente, enquanto o enunciador do discurso religioso representa a figura imortal, eterna, infalível e todo-poderosa distante do público, esse público é mortal, falível e de poder relativo. Com as redes sociais, o enunciador se aproxima desse público e interage com ele. Tal proximidade humaniza o representante religioso, que 


\section{miDiA

posta nas redes sociais mensagens com reflexões religiosas e aconselhamentos morais, mas também trivialidades, agendas de compromissos públicos e experiências e opiniões pessoais sobre temas não-relacionados à religião. Além de assumir fraquezas e sentimentos que o colocam como um ser humano como outro qualquer, o padre também desenvolve um "ethos de virtude", transparecendo sinceridade e retidão, e um "ethos de caráter", vinculado a equilíbrio e correção de comportamento (MELO, 2015, p.80-84).

Tanto Rossi como Fábio de Melo investiram não apenas em um discurso evangelizador que os aproxima dos fiéis, mas em uma aparência física máscula e atlética, à qual se associam também vigor físico, beleza, juventude e força (FERNANDES, 2005, p.132). Dotado de um olhar calmo e pacífico, Rossi é alto e, ao longo de grande parte de sua carreira, teve um corpo forte, próximo ao de um esportista. Ele é formado em Educação Física e, antes do sacerdócio, manteve relacionamentos amorosos com mulheres, tendo descoberto a vocação para o sacerdócio após a morte de um primo em um acidente de carro e a notícia do tumor maligno de uma tia. Após um período de depressão, que o fez engordar, e de uma dieta rigorosa, que o fez pesar 60 quilos, hoje Rossi procura retomar uma aparência saudável e máscula, justificando que a manutenção de um bom físico e de uma boa saúde era fundamental para o exercício de sua missão evangelizadora enquanto um homem cuja vida é "dedicada a Deus" (HARTMANN, 2006, p.21; MARRA, 2015). Já Fábio de Melo assumia ter vaidade e argumentava que havia muita "gente feia" na Igreja por conta de uma "mentalidade antiga". Pela beleza e pela preocupação com a saúde, fazia atividade fisica. Além disso, cuidava também das vestimentas, marcadas pela elegância, visível no uso de marcas renomadas (NÓBREGA, 2009, p.9).

O objetivo do artigo é examinar as representações de virilidade nos perfis dos padres Marcelo Rossi e Fábio de Melo no Instagram. O argumento central sustenta que, apesar das diferenças em termos de linguagem e de abordagem de temas entre os dois, ambos os padres mobilizam a simplicidade e o apelo emocional, típicos da virilidade sacerdotal, ao reforçarem em seus posts a posição institucional de mediação entre Deus e os fiéis. Eles aliam a tais elementos fatores ligados à lógica do mercado e enfatizam simultaneamente aspectos de virilidade associados à beleza, à juventude, ao despojamento e até mesmo a um erotismo sutil, permitindo uma maior aproximação do 


\section{míDiA \\ 保 \\ DiAno}

sacerdote com seus seguidores. Neste estudo, foi feita uma pesquisa qualitativa das postagens dos dois padres em seus perfis no Instagram desde janeiro até maio de 2017. Numa primeira etapa da pesquisa, as postagens foram categorizadas a partir de temas como agendas de eventos profissionais, promoção de bens culturais ligados à religião, ajuda espiritual e assuntos não-religiosos. Posteriormente, essas postagens foram analisadas à luz da discussão conceitual e teórica apresentada acerca da virilidade sacerdotal nos meios de comunicação, em especial nas novas tecnologias. No próximo item do artigo, será discutido o conceito de virilidade sacerdotal e, em seguida, a virilidade dos padres midiáticos. Logo depois, investigarei como a virilidade sacerdotal se apresenta diante do desenvolvimento das novas tecnologias. Antes de tecer as considerações finais, examinarei as representações de virilidade dos padres midiáticos no Instagram.

\section{A virilidade sacerdotal}

Durante a Idade Média, o clérigo era visto como carente de virilidade, pois não trabalhava nem guerreava. A castidade, a humildade e a fidelidade eram virtudes dele que também caracterizavam a honra feminina. Com a Reforma Protestante, calvinistas e luteranos acusavam padres católicos de insuficiência viril. O próprio estilo imberbe do clérigo marcava uma espécie de infantilização, como se a renúncia à barba fosse também uma renúncia à função sedutora e sexual da pilosidade. Porém, para esses clérigos, a virilidade não estava na aparência, mas no comportamento: ainda que eles escapassem às práticas que geralmente construíam coletivamente a virilidade - como a caça, os duelos e o interesse pelas moças -, o clérigo se via como um servidor de Deus e dos pobres. A defesa da solidariedade clerical paroquial - com noções de caridade, benquerença, serviço, sacrifício, desempenho e honra - eram expressões de sua virilidade, de maneira que a autoridade do padre era respeitada e temida (LE GALL, 2013).

Desde meados do século XVI até o fim do século XVIII, ser padre significava a incorporação de hábitos que se distanciavam da expansiva virilidade popular, sem, no entanto, assemelhar-se às elites. $\mathrm{O}$ sacerdócio supunha o completo autocontrole dos desejos sexuais e a impossibilidade de cópula livre. A virilidade alternativa construía-se 


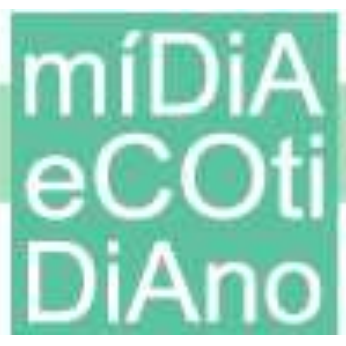

a partir da discrição, do desapego dele mesmo e do sacrifício da coragem discreta do "servo de Deus". O controle das paixões e do caráter limitava a exteriorização de uma virilidade flamejante. A aplicação contínua da vontade de atingir um objetivo fixado permitia aos padres reivindicar a sua virilidade como a verdadeira contra os modelos dominantes. Entretanto, muitos padres não se enquadravam mais nesse tipo de virilidade no começo do século XIX. A embriaguez, a violência e a devassidão encontravam-se no comportamento de sacerdotes ao longo deste século, enquanto outros - considerados escandalosos - questionavam a "civilização de costumes", parte integrante do ser sacerdotal. Com a universalização do anticlericalismo, os desvios tornavam-se mais visíveis, principalmente quando exacerbavam conflitos locais e tensões políticas. Em resposta a isso, no século XIX, a formação do clero para a civilidade afirmava a dignidade eclesiástica, tornando-se tal movimento necessário para canalizar os efeitos de iniciativas pastorais do movimento católico, caracterizadas pelo engajamento físico e viril desde o seminário. Nesse contexto, os padres se afirmavam como os únicos capazes de apresentar a real virilidade - aquela do caráter moral - aos adolescentes. A convergência com a virilidade dominante se explica em parte pela experiência militar que os padres conheciam. Apoiados por iniciativas pastorais, os seminaristas articulavam a virilidade sacerdotal e militar. $O$ autocontrole parcialmente afetivo integrava-se, no final do século XIX, mais à potência física (AIRIAU, 2013).

Ao pré-adulto, dever-se-ia ensinar o código de virilidade baseado em bravura, honra, lealdade, vontade de dominação e superioridade em relação às mulheres. Nesse processo, a educação cristã trazida pelos padres apontava que o dever do adolescente consistia em amar a Deus e a seus pais, irmãos, Pátria e trabalho. O menino deveria se mostrar bom, correto, casto e submisso. A educação cristã - que encontrava equivalentes na moral laica - apontava que tornar-se homem não consistia em mostrarse grosseiro ou brutal, mas modesto e trabalhador, com o exercício do autocontrole, do fair play, da solidariedade e da camaradagem (JABLONKA, 2013). Ao longo da infância e adolescência, os meninos eram levados a interiorizar formas de pensamento e maneiras de agir que os preparavam para a tomada de posição no encadeamento das relações de poder e dominação. $\mathrm{O}$ menino se tornava homem, porque, à medida que se realizava o trabalho de maturação biológica, as instituições que participavam da sua 


\section{míDiA \\ eCO \\ DiAno}

socialização encarregavam-se de transmitir a ele o hábito viril, o conjunto de disposições físicas e psíquicas que lhe permitiriam desempenhar seu papel de homem uma vez chegada a maturidade. A partir do século $\mathrm{XX}$, os movimentos de juventude católica traziam uma garantia religiosa que tranquilizava os pais, ao mesmo tempo em que ofereciam meios a esses meninos de escapar temporariamente do controle familiar e compartilhar a liberdade com amigos. Esses movimentos viam no adolescente a reserva de energias vitais a ser canalizada e exaltavam a vitalidade e o vigor físico e moral do homem em formação (BAUBÉROT, 2013).

As funções do sacerdote se redefinem num contexto em que o campo midiático começa a trazer transformações nas formas de religiosidade na segunda metade do século XX. Diante dos dilemas materiais e espirituais das pessoas, as Igrejas - dentre elas, a Católica - instituem práticas terapêuticas nas novas mídias a fim de trazerem respostas às demandas mais imediatas e urgentes colocadas pelos fiéis. Ao se deslocarem da dimensão do templo para o espaço da TV e, mais recentemente, para as novas mídias digitais, os sacerdotes desenvolvem novos conjuntos de ações simbólicas para a definição de formas de relacionamento com seus seguidores. São deixadas de lado nessas novas plataformas as maneiras tradicionais de comunicação dos rituais religiosos e as experiências de grupos nas Igrejas e são instauradas estratégias de mídia de massa que reorganizam a experiência religiosa. A virilidade sacerdotal, nesse contexto, define-se a partir da conferência, ao sacerdote, de um papel mediador e regulador em uma nova "comunidade terapêutica", empreendedora de projetos de cura e salvação, papel este apoiado e legitimado pelos fiéis. $\mathrm{O}$ projeto pedagógico desenvolvido pelo sacerdote funda-se na autoridade que ele detém enquanto conselheiro e auxiliador na construção de novos exercícios de interioridades como resposta ao desamparo e aos infortúnios de seus seguidores. Trabalhando no âmbito da publicidade espiritual, o padre assume o poder de desenvolver, a partir da sugestão e da orientação espirituais, novas vivências emocionais em seus fieis, trazendo pedagogias que supõem novas formas de confiança e de proximidade com esses seguidores na "empreitada da salvação" (FAUSTO NETO, 2002, p.152-163).

$\mathrm{Na}$ construção dessas novas formas de proximidade, a virilidade sacerdotal manifesta-se na concepção do padre como um ser humano como qualquer outro, na 


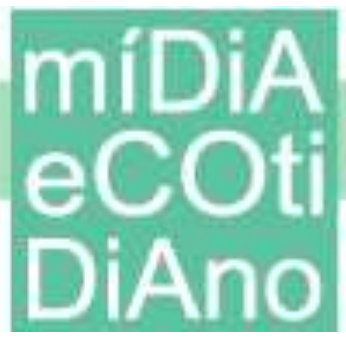

condição de um "amigo virtual" com a qual os fieis se identificam, mas dotado da autoridade para o direcionamento espiritual a fim de auxiliá-los no enfrentamento das mazelas da vida. A mediação que ele promove entre Deus e os seus seguidores repagina noções de autoridade, autocontrole e honra associadas à virilidade sacerdotal e que conferem ao padre liderança espiritual no ambiente virtual. Essa mediação faz-se necessária, pois o sobrenatural alimenta a curiosidade por não poder ser visto, tocado ou sentido diretamente; nesse sentido, cabe ao padre viabilizar esse diálogo com as entidades religiosas, na esperança de que a realidade possa se harmonizar com os desejos dos homens (NASCIMENTO; GARCIA JÚNIOR, 2013). O exercício dessa mediação pelo padre não pode pressupor, assim, o distanciamento da vida cotidiana de seus fiéis. Isso implica que, ao mesmo tempo em que a comunicação desenvolvida por ele nas novas mídias traga elementos de direcionamento espiritual típicos da virilidade eclesiástica, ele busque reforçar na sua identidade pontos de virilidade do cidadão comum para estimular a identificação e reduzir o distanciamento na interação com seus seguidores (FERNANDES, 2005, p.132), como o uso de roupas masculinas mais informais em vez da batina, a preocupação com o corpo e com a exposição da realização de atividades físicas e do cuidado com a beleza - por vezes aproximando-se de estratégias de sedução típicas de homens não-envolvidos na atividade religiosa - e a manifestação de posicionamentos sobre eventos da vida cotidiana com informalidade e até mesmo ironia.

\section{A virilidade dos padres midiáticos}

Em 1963, o Papa Paulo VI publicou um decreto que defendia que todos os meios de comunicação poderiam ser utilizados para a atuação católica (SANTOS; CAPPARELLI, 2004, p.3). No Brasil, o despontar do "tele-evangelismo" deu-se na década de 1970 profundamente inspirado em um modelo norte-americano, em que líderes religiosos alugavam horários na TV para proferir mensagens evangélicas numa combinação de reza, cura e salvação. A TV era utilizada para a divulgação de suas ações, e essa possibilidade de exploração do espaço televisivo foi amplamente cogitada também pela Igreja Católica. Para usar aquele espaço, tal Igreja deveria adaptar seu discurso, mesmo com a resistência interna de bispos e sacerdotes que apontavam para a 


\section{míDiA

perda de sacralidade da missa que fosse exposta na tela (PATRIOTA, 2009, p.184-186).

A transmissão de missas tornou-se corrente, e gradualmente se viu que não só a TV, mas plataformas trazidas pela internet como as redes sociais permitiriam a fabricação em série de imagens e entretenimento, suscitando desejos e ansiedades no consumidor religioso. Trouxe-se a esse consumidor a atividade religiosa na forma de shows para serem assistidos e consumidos e de programas religiosos que afetam os indivíduos emocionalmente durante sua apreciação voluntária (PATRIOTA, 2008). Esse apelo emocional se fortalece no caso específico do Brasil, uma vez que a música e a dança aparecem como recursos fundamentais para disseminação e apropriação de doutrinas. Tal fator, somado à possibilidade de entretenimento, fortalece $\mathrm{o}$ movimento de espetacularização e mercantilização da fé. A música não se coloca apenas como expressão litúrgica, mas como mediação do sagrado, e se articula com a mídia e o consumo, trazendo condições para a ascensão de "padres midiáticos" como Rossi e Fábio de Melo (FREITAS JÚNIOR, 2009, p.202-203). Além disso, a adoção crescente de uma dimensão mais comercial pela religião - inclusive o Catolicismo - veio marcada pela disseminação de mensagens que giravam em torno de inseguranças, medos, solidões e incertezas dos indivíduos, como nos EUA; porém, no caso brasileiro, inúmeros religiosos se valiam de supostas intervenções divinas e recursos psicologistas permeados de promessas de cura ou salvação alimentando-se da miséria extrema de grande parte da população (ASSMANN, 1986, p. 80). Rossi e inúmeros de seus sucessores como Fábio de Melo mobilizaram esses discursos, colocando-se como intermediadores entre os fiéis e o fenômeno divino a partir de sua produção cultural.

O "tom mágico" da pregação baseia-se nas ideias de reza, cura e salvação e na mobilização de padres midiáticos, que, além de sacerdotes, são artistas ou esportistas que utilizam os meios de comunicação não apenas como espaços estratégicos na conquista de fieis, mas como ferramentas de publicidade para produtos orientados ao consumidor religioso (SANTOS; CAPPARELLI, 2004, p.4-8). Nesse contexto, o evangelismo de Rossi e Fábio de Melo parte da constatação de uma gradual diminuição de processos comunitários coletivos e de celebrações litúrgicas presenciais diante do aumento de comunidades virtuais para o consumo individual de bens simbólicos associados à fé. Nesse consumo de bens culturais, o artista individual - neste caso, o 
padre - ocupou o palco, enquanto o fiel acomodou-se na plateia do líder religioso com a oferta de promessas, objetos ou dinheiro num "espaço de troca" em que a divindade é pressionada a responder com um "milagre" como emprego, saúde, dinheiro ou sorte. O fiel não enxerga uma necessidade maior de vivência e celebração comunitária da fé, preocupando-se mais com respostas imediatas de representantes da Igreja Católica à sua necessidade imediata de felicidade. Essa Igreja, por sua vez, oferece ao fiel um microespaço de prática religiosa sob o perigo de perder fiéis. Nesse contexto, empresários de diferentes mídias se apropriam do produto religioso para gerar ganhos econômicos, fazendo da religião uma estratégia de ganho de audiência e uma fonte de lucro. Eles entenderam que símbolos, mitos e toda uma linguagem religiosa são de fácil assimilação e conversão para a linguagem midiática e geram muita emoção no público, de forma que o cardápio diversificado de programas e produtos religiosos invadiu diferentes meios de comunicação. A sustentação da atividade evangelizadora de Rossi e de Fábio de Melo conta com máquinas econômicas empresariais e instrumentos de marketing profissional capazes de garantir sucesso de público e vendagem de seus produtos ao se adaptarem às exigências das diferentes mídias em termos de linguagem e de uma interpretação mais flexível das disposições e normas católicas. Ídolos como os dois padres considerados neste estudo surgem em resposta à necessidade sentimental relacional dos fiéis e oferecem gancho de vendagem de produtos múltiplos. Ainda que se coloquem como "servos do Senhor" ou "instrumentos do Senhor Jesus", eles extrapolam essas funções $\mathrm{e}$ frequentemente se tornam referentes únicos $\mathrm{e}$ paradigmáticos da fé das pessoas (HARTMANN, 2006, p.4-9).

Rossi foi um dos precursores da figura do "padre cantor" ou do "padre artista". Ainda que demonstrasse limitações vocais e acadêmicas, ele retomava músicas do repertório católico tradicional e produzia algumas novas canções, aparecendo em múltiplas mídias e batendo recordes de vendas em toda a sua produção, como CDs, DVDs, revistas e outros artigos religiosos. As celebrações no espaço privado chegam ao espaço público de praças e estádios, transformando-se em megashows religiosos nos quais Rossi é a principal estrela (HARTMANN, 2006, p.19-20). Tais shows ocorrem em inúmeras partes do Brasil, país no qual o Catolicismo eclesial e/ou nominal veio perdendo influência lentamente por conta do maior pluralismo religioso e pela 


\section{eco \\ DiAno}

secularização crescente dos mecanismos estruturantes da sociedade. $O$ carisma mobilizado por Rossi difere do pentecostalismo por demonstrar sua obediência à hierarquia. O padre mantém vestes litúrgicas e segue à risca a liturgia da missa (BOBSIN, 1999, p.110-111). Nesse sentido, ele difere de Fábio de Melo, que utiliza um vestuário moderno e transforma parte de suas missas em palestras sobre fé e condutas condizentes com os ensinamentos de Deus. Entretanto, ambos desenvolvem uma imagem viril associada ao profissionalismo e à devoção, utilizando grande parte dos recursos obtidos com a venda de seus bens religiosos para doações. Colocando-se em contraposição a concorrentes pentecostais, ambos criticam igrejas nas quais pastores pedem dinheiro como uma espécie de obrigação religiosa do fiel (FREITAS JÚNIOR, 2009, p.204). Ainda que Rossi e Fábio de Melo procurem imprimir suas marcas próprias na performatização da vivência sacerdotal, ambos sustentam a universalização da instituição católica e, por conta de seu carisma, permitiram consolidar em seus fiéis uma imagem até mesmo heróica ao conquistarem o retorno de pessoas que tinham deixado o Catolicismo e trazerem novos fieis para a Igreja (FERNANDES, 2005, p. 133; BRONSZTEIN; ALVES, 2014; SOUZA, 2002, p. 93-94).

\section{A virilidade sacerdotal e as novas tecnologias}

Como desenvolvido acima, a mobilização dos meios de comunicação por igrejas não é um fenômeno inovador, mas a frequência de utilização e a diversidade de dispositivos midiáticos hoje cresceram exponencialmente, em particular as mídias digitais, com a geração de métodos múltiplos de evangelização. O Catolicismo evidencia o forte apelo para a utilização de recursos midiáticos em face do desafio colocado por outras expressões de religiosidade e espiritualidade, midiatizando seu discurso a fim de acessar um público mais amplo e diverso e trazendo para representantes religiosos a necessidade de desenvolver novas formas de interagir com os fiéis. Num contexto em que a Igreja Católica busca manter uma imagem de renovação e modernidade para sustentar e resgatar sua base de fiéis, o maior capital social de seus representantes está ligado à maior visibilidade nas redes, à melhoria da reputação perante outras pessoas, à maior autoridade que o conhecimento religioso atribui aos padres, à popularidade maior com números mais expressivos de curtidas e comentários 
de suas postagens e ao maior suporte social ao retornarem a um grande número de solicitações. No caso de uma rede como o Instagram, as imagens e os vídeos postados permitem a difusão de ensinamentos e práticas baseadas nos valores do Catolicismo que parecem vir não de uma instância hierarquicamente superior, mas de alguém com quem se tem identificação e simpatia, como um amigo que aproxima o sagrado e o profano (MELO, 2015, p.72-73, 77-79, 84). A comunicação ali estabelecida permite uma interação constante, que viabiliza também a divulgação de CDs, livros e outros produtos a partir da sedução dos fieis por meio de apelos emocionais que conectam a esperança de melhoria de vida e a crença em Deus ao consumo de tais bens (SILVA, 2015, p.1-3, 6-11).

Diante do esforço das instituições religiosas de desenvolver métodos mais eficazes de comunicação da sua mensagem, as novas tecnologias trouxeram novas formas de vivência da fé, como as capelas virtuais, num contexto de avanço do individualismo religioso e de desregulamentação institucional vivida pelas religiões. Novas tradições religiosas são estabelecidas, como as visitas constantes de fiéis a sites religiosos ou a perfis de religiosos em redes sociais como os dos padres midiáticos, que personalizam palavras, sons e imagens mediante o gosto dos indivíduos. Esses fiéis podem buscar informações como agendas de eventos dos padres, bens culturais ligados à religião - revistas, livros, medalhas, textos, orações, músicas e cartões, por exemplo e ajuda espiritual diante de solicitações como a cura de doenças, a proteção para parentes e amigos, o amparo pelo falecimento de alguém, a proteção à alma do falecido, o sucesso financeiro, o agradecimento de graças alcançadas e o apoio psicológico, por exemplo (ANDRADE, 2007, p.177-184). Nas redes sociais, os padres midiáticos atraem um grande número de seguidores, que interagem entre eles e com os padres a partir das postagens realizadas pelos sacerdotes. Se por um lado os sacerdotes buscam acolher seus seguidores abordando temas que os afligem, também se apropriam de técnicas de mercado para estimular o consumo de bens, mesmo se sabendo que o consumo é uma das principais causas de pressão social (FREIRE, 2015, p.4, 10-13). 


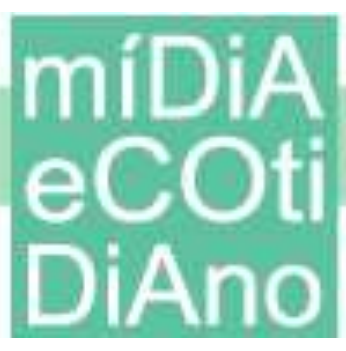

A virilidade dos padres midiáticos no Instagram

O Instagram viabiliza o compartilhamento de fotos e vídeos entre seus usuários, a aplicação de filtros digitais e a disponibilização de arquivos em outras redes como o Facebook. Usuários do Instagram utilizam-no como diário virtual ou forma de divulgação do estilo de vida em uma vitrine virtual (HU et al., 2014). Surgem, assim, dinâmicas de sociabilidade quando usuários atualizam permanentemente informações e constroem imagens deles mesmos. Tais imagens estipulam gostos atribuídos a comportamentos, atitudes e escolhas (CARRERA, 2012, p.149-151), que contribuem para a manutenção de uma fachada do ator social, definida em termos de atributos sociais valorizados (GOFFMAN, 2011, p.14-15). Essa manutenção é facilitada no Instagram pela possibilidade de administração das respostas de interlocutores e das interações com os seguidores dos perfis de tais usuários (CARRERA, 2012, p.159; SIBÍLIA, 2008, p.235-236).

Durante as celebrações de suas missas, tais padres mobilizam técnicas corporais como o canto, os gestos e a dança, as quais buscam primordialmente o louvor a Deus e a realização de um contato íntimo com a divindade, o que se expressa como uma forma de êxtase (MAUÉS, 2003, p.13-14). O corpo continua sendo mobilizado por tais padres como instrumento no Instagram. No caso do perfil de Rossi (@padremarcelorossi) que traz a definição do padre como "um sacerdote católico brasileiro, conhecido pelo trabalho de evangelização que realiza" e conta com 583 mil seguidores no início de maio de 2017 -, o corpo do sacerdote é retratado em fotos e vídeos durante os rituais religiosos, nos quais se enfatiza seu domínio do altar e da multidão que assiste à cerimônia. No caso de grande parte dos vídeos, Rossi aparece pregando, dançando e animando a multidão de fiéis em templos religiosos. Em outros, a imagem focaliza o rosto do padre, que aparece enviando mensagens de louvor e de paz, conduzindo orações no tom de voz tipicamente sereno e abençoando os seguidores. Outras postagens trazem montagens de fotos e vídeos de imagens religiosas - gravuras de santos, velas, cruzes e terços - com orações (como a de São Francisco de Assis), citações de trechos bíblicos ou de falas de autoridades religiosas como o Papa Francisco e o reforço da necessidade de se seguirem os ensinamentos divinos ("Jesus é o único caminho. O resto é beco sem saída”, “A oração de um justo é poderosa e eficaz”). 


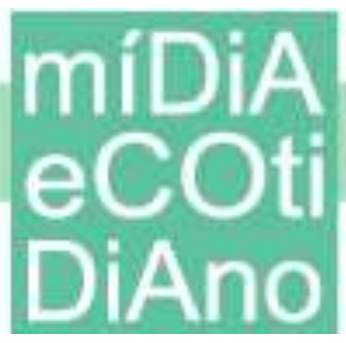

Algumas postagens de Rossi chamam a atenção para a celebração de dias de santos específicos (São Filipe, São Tiago, São Bento e São José em postagens recentes), e, em menor número, para atividades de sua agenda de compromissos religiosos em igrejas, santuários ou mesmo conversas com fiéis pelas redes sociais e a divulgação de seus produtos religiosos. As postagens de Rossi no Instagram raramente falam de aspectos da sua vida pessoal. As legendas das fotos e dos vídeos em geral são simples com mensagens de "bom dia", "boa semana" ou a descrição breve do evento retratado ou trazem trechos da Bíblia ou de ensinamentos religiosos. Nos comentários a esses posts, os fiéis corroboram a autoridade religiosa de Rossi em geral com respostas como "Amém", "Deus seja louvado" e "Deus te abençoe" ou então sinalizando que o padre seria "uma bênção" em suas vidas ou um "enviado de Deus". Esses fiéis sentem-se, assim, mais próximos do sacerdote e partes mais atuantes do fenômeno religioso ao comentarem as mensagens colocadas pelo padre. Grande parte dos posts está centrada na figura de Rossi como o líder do ritual religioso - que, por exemplo, carrega o Santíssimo Sacramento e fala para a multidão a sua mensagem de fé - e o propagador da mensagem que permite mediar o contato dos fiéis com a experiência divina. Existem comentários críticos como "Você só prega mentira", mas eles são raros. O único perfil que Rossi aparece seguindo no Instagram é o do Papa Francisco.

O estilo impresso por Fábio de Melo em seu perfil no Instagram (@ pefabiodemelo) contrasta em alguns pontos com a imagem que Rossi constrói dele mesmo na rede. Fábio de Melo conta com muito mais seguidores que Rossi - 4,5 milhões - e segue 344 perfis, dentre os quais estão os de atores, cantores, apresentadores de TV, bloggers, modelos, atletas e perfis sobre musculação e dicas fitness. Na definição do seu perfil, Fábio de Melo diz que é "de cada povo um pouco" e que o seu lugar é "hoje a terra inteira", situando-se como um sacerdote moderno e globalizado. O tom mais sereno e focado no discurso religioso de Rossi contrasta com o teor mais irônico e despojado de Fábio de Melo, que, de forma distinta a Rossi, raramente aparece nas fotos e vídeos no Instagram com batina. Fábio de Melo em geral aparece usando camisas sociais em eventos públicos ou em programas de TV dos quais participa, roupas de marcas caras em seus shows - em cujos posts ele em geral agradece ao público presente - e vestimentas utilizadas para a realização de atividades físicas nas 


\section{miDiA \\ ecot \\ DiAno}

fotos que tira na academia. Em grande parte das fotos, Fábio de Melo aparece em situações da vida cotidiana ao lado de celebridades, membros de sua equipe, pessoas de seu convívio social direto e fiéis, enquanto Rossi aparece dando depoimentos de conteúdo religioso sozinho ou exercendo sua função eclesiástica em templos para multidões. Em algumas fotos e vídeos, Fábio de Melo utiliza filtros jocosos que distorcem a imagem de seu rosto e inserem máscaras como anjo e cachorro em sua face. Em outros posts, ele insere piadas e ironias, como uma montagem com a mensagem "Daqui a pouco já será segunda-feira" e a imagem de um gato chorando. Em outro post, ele retrata o ex-apresentador do Jornal Hoje da TV Globo, Evaristo Costa, sentado na bancada do jornal e insere um desenho malfeito dele mesmo ao lado de Costa com a legenda "Hoje eu tive o imenso prazer de visitar o presidente da internet, o meu amigo @ evaristocostaoficial em seu local de trabalho. Conheci os bastidores do JH e ao final fui gentilmente convidado por ele para registrar nosso encontro com uma fotografia na bancada".

Em contraste à pouca ênfase de Rossi em sua vida privada, Fábio de Melo retrata-se em cenas em seu lar brincando com seus cachorros ou fazendo piadas com amigos, muitos deles pessoas famosas. Fábio de Melo desenvolve postagens com mensagens de conteúdo religioso como Rossi, mas predominantemente de autoria própria: "Que Deus nos defenda das ruindades calmas, dos ódios que sorriem, que não alardeiam, que caminham entre nós nos andores da falsidade. Pe. Fábio de Melo”. Além disso, ele também insere pensamentos não necessariamente vinculados com a religião (“Conte com a opinião de quem a pediu”), mas em geral também de autoria própria: 'Uma ofensa só ofende quando permitimos. Se não concedermos autoridade ao que nos foi dito, a palavra ofensiva perde o poder de ofender. Pe. Fábio de Melo". Bem mais frequentemente do que no perfil de Rossi, Fábio de Melo utiliza o Instagram para a divulgação de seus shows e produtos, como o seu último $\mathrm{CD}$, "Clareou", inclusive com cenas da gravação do álbum no estúdio. Os usuários respondem frequentemente elogiando o conteúdo dos posts (em geral com emojis de aplausos) e o próprio sacerdote ("esse padre é demais", "Padre, você é dez !", "você é lindo"). São frequentes comentários que elogiam a linguagem despojada e dinâmica do padre ("Primeiro padre que conheço que seja tão moderno no mundo da tecnologia"). Comentários críticos 


\section{míiA

aparecem com maior frequência do que no perfil de Rossi, em especial em face do que alguns usuários consideram uma postura excessivamente informal por parte de Fábio de Melo. Alguns inclusive sugerem que o padre seria homossexual.

Numa frequência bem maior do que no perfil de Rossi, a exaltação de um estilo de vida glamouroso e o contato próximo com celebridades conjugam-se nas postagens de Fábio de Melo com fatores como beleza, juventude e sutil erotismo que o caracterizam como uma estrela. $\mathrm{Na}$ interface com a cultura de massa por meio do visual e do discurso, o padre parece estabelecer um gancho para inserção do Catolicismo recente nos meios de comunicação e, ao mesmo tempo, divulgar seus produtos e sua própria imagem (NÓBREGA, 2009, p.10-11). Enfatizando sua origem mais humilde, ele ainda projeta a imagem de homem de sucesso capaz de vencer as adversidades não somente pelos esforço e talento próprios, mas pela implementação das orientações religiosas na sua vida (MENDONÇA, 2013). Ele também se coloca mais próximo da vida cotidiana dos fieis pelo uso do humor e do tratamento de temas não-religiosos que o distanciam da imagem de um representante religioso mais austero.

\section{Considerações finais}

Ainda que o Brasil se mantenha como o maior Estado católico do mundo, o número de seguidores da Igreja Católica foi amplamente reduzido, e os preceitos católicos vieram gradualmente deixando de definir hábitos e costumes da população, particularmente no que tange a conduta sexual. A legitimidade moral dessa Igreja é ainda questionada por conta de denúncias de pedofilia cometida por sacerdotes. Diante disso, muitos fiéis optaram por abandonar totalmente a religião ou adotar outras fés num contexto de profusão de múltiplas ofertas alternativas de cura e salvação dos males. Nesse contexto, os padres midiáticos assumiram papel fundamental na manutenção de fiéis e na captação de novos adeptos do Catolicismo ao oferecerem consolos espirituais e ensinamentos que conferem mais sentido para a vida e o mundo. A renovação popularizadora trazida por tais padres é bastante imagética e pautada na transmissão de mensagens simples e de fácil compreensão mesmo para pessoas não-familiarizadas com valores católicos (SOUZA, 2007, p.156-161). 
Porém, como lembra Cecîlia L. Mariz (2003, p.176-177), para que os valores e princípios trazidos pelos padres ligados à RCC possam se sustentar, faz-se necessário que a dinâmica social e histórica traga novas regras que institucionalizem o carisma, sob o risco de esse carisma desaparecer. É fundamental uma maior consolidação da estrutura administrativa para a organização desse movimento em face de seu crescimento, inclusive nas redes digitais MARIZ, 2003, p.176-177). Uma maior organização permite um crescimento mais harmônico e propenso ao diálogo diante do contexto de crise das "estruturas fechadas" da religião mediante a mobilização de "sistemas abertos de conhecimento", com a maior comunicação entre povos e culturas, a percepção mais clara acerca da pluralidade religiosa, a maior proximidade do Cristianismo com outras tradições religiosas e a existência de novos canais de conhecimento sobre valores espirituais múltiplos (TEIXEIRA, 2012, p.1). O Catolicismo consegue, assim, apresentar-se cada vez mais permeável à modernidade ao se adaptar criativamente a um novo panorama religioso que se define no Brasil, com a secularização e a diferenciação religiosa (CAMURÇA, 1998).

Apesar das claras diferenças de linguagem e de tratamento de temas por Rossi e Fábio de Melo em seus perfis no Instagram, os padres midiáticos tocam questões religiosas e não-religiosas que permeiam o cotidiano dos seguidores e se apresentam em veículos seculares, estreitando as relações entre a Igreja Católica e os fiéis. Eles mobilizam canais seculares de comunicação e inovam nos rituais e na assimilação das técnicas de comunicação, mas sustentam fortemente sua posição institucional como sacerdotes por meio de sinais distintivos de sua condição de mediadores entre Deus e os fiéis. A simplicidade e o apelo emocional típicos da virilidade sacerdotal aliam-se a elementos da lógica de mercado, ofertados para o consumo (FERNANDES, 2005, p.142-145), como o humor em posts de Fábio de Melo. A exposição midiática desses padres afirma-os como atores sociais merecedores de destaque na vida comunitária e social, dotados de legitimidade por suas posições e atitudes aprováveis e exemplares perante indivíduos que buscam a afirmação de novas identidades coletivas e individuais (BRONSZTEIN; ALVES, 2014). Tais padres - que são ao mesmo tempo cantores, apresentadores e escritores comercialmente bem-sucedidos em todas as áreas de atuação - desenvolvem uma virilidade associada à beleza, à juventude e até mesmo a um 
erotismo sutil, que rompem com a imagem de virilidade sacerdotal mais tradicional e permitem uma maior aproximação do sacerdote com os fiéis (NÓBREGA, 2009, p.12).

\section{Referências}

AIRIAU, Paul. A virilidade do padre católico: certa ou problemática ? In: CORBIN, Alain; COURTINE, Jean-Jacques; VIGARELLO, Georges. (Ed.) História da Virilidade - Volume 2: O triunfo da virilidade. O século XIX. Petrópolis: Vozes, 2013, p.302-320.

ANDRADE, Péricles. Ciberespaços sagrados: as capelas virtuais no catolicismo contemporâneo. Estudos de Sociologia, v. 13. n. I, p. 175.194, 2007.

ASSMANN, Hugo. A Igreja Eletrônica e o seu Impacto na América Latina: convite a um estudo. Petrópolis: Vozes, 1986.

BAUBÉROT, Arnaud. Não se nasce viril, torna-se viril. In: CORBIN, Alain; COURTINE, Jean-Jacques; VIGARELlO, Georges. (Ed.) História da Virilidade Volume 3: A virilidade em crise ? Séculos XX-XXI. Petrópolis: Vozes, 2013, p.189220 .

BOBSIN, Oneide. Tendências religiosas e transversalidade: Hipóteses sobre a transgressão de fronteiras. Estudos Teológicos, v. 39, n. 2, p. 105-122, 1999.

BRONSZTEIN, Karla Patriota; ALVES, Maria Lúcia Bastos. Mega-eventos e espetáculos religiosos: novas singularidades na sociedade de consumo. Animus, v. 13, n. 26, s.p., 2014.

CAMURÇA, Marcelo. Sombras na catedral: a influência New Age na Igreja Católica e o holismo da Teologia de Leonardo Boff e Frei Betto. Numen, v. 1, n. 1, p. 65-80, 1998.

CARRANZA, Brenda. Catolicismo Midiático. Aparecida: Ideias \& Letras, 2011.

CARRERA, Fernanda. Instagram no Facebook: uma reflexão sobre ethos, consumo e construção de subjetividade em sites de redes sociais. Animus, v.11, n.22, p.148-165, 2012.

FAUSTO NETO, Antônio. Processos midiáticos e construção de novas religiosidades: dimensões discursivas. Galáxia, n. 3, p. 151-164, 2002.

A religião do contato: estratégias discursivas dos novos "templos midiáticos". Contemporânea, v. 2, n. 2, p. 139-168, 2004. 
FERNANDES, Sîlvia Regina Alves. Padres cantores e a mídia: representações da identidade sacerdotal. Ciências Sociais e Religião, Ano 7, n. 7, p. 131-155, 2005.

Sobre artífices e instrumentos: o estudo da religião no Brasil e algumas tendências metodológicas. Estudos Sociológicos, v.18, n.34, p.19-37, 2013.

FREIRE, Adriana do Amaral. A comunidade do Padre Marcelo Rossi no Facebook numa perspectiva de autopromoção e uso mercadológico do espaço. In: $2^{\circ}$. SIMPÓSIO NORDESTE DA ABHR. Anais..., Recife, 2015, p. 1-16.

FREITAS JÚNIOR, Antônio Luiz de. Pistas teológico-práticas sobre a relação entre mídia televisiva e religião a partir do caso Marcelo Rossi. Caminhando, v. 14, n. 2, p. 195-207, 2009.

GOFFMAN, Erving. Ritual de interação: ensaios sobre o comportamento face a face. Rio de Janeiro: Vozes, 2011.

HARTMANN, Atîlio. Religiosidade Midiática: Uma Nova Agenda Pública na Construção de Sentidos? Revista IHU Online, n.9, p.1-23, 2006.

HU, Yuheng; MANIKONDA, Lydia; KAMBHAMPATI, Subbarao. What We Instagram: A First Analysis of Instagram Photo Content and User Types. Association for the Advancement of Artificial Intelligence website, 2014. Disponível em: <http://149.169.27.83/instagram-icwsm.pdf $>$. Acesso em: 8 set. 2016.

JABLONKA, Ivan. A infância ou a "viagem rumo à virilidade". In: CORBIN, Alain; COURTINE, Jean-Jacques; VIGARELLO, Georges. (Ed.) História da Virilidade Volume 2: O triunfo da virilidade. O século XIX. Petrópolis: Vozes, 2013, p.37-73.

LE GALL, Jean-Marie. A virilidade dos clérigos. In: CORBIN, Alain; COURTINE, Jean-Jacques; VIGARELLO, Georges. (Ed.) História da Virilidade - Volume 1: A invenção da virilidade. Da Antiguidade às Luzes. Petrópolis: Vozes, 2013, p.242-263.

MARIZ, Cecilia L. A Renovação Carismática Católica: Uma igreja dentro da Igreja? Civitas, v.3, n.1, 2003, p.169-186.

MARRA, Heloisa. Padre Marcelo Rossi: uma vida dedicada a Deus. Rio de Janeiro: Best Seller, 2015.

MAUÉS, Raymundo Heraldo. "Bailando com o Senhor": técnicas corporais de culto e louvor (o êxtase e o transe como técnicas corporais). Revista de Antropologia, v. 46, n. 1, p. 9-40, 2003.

MELO, Mônica Santos de Souza. A Utilização das Redes Sociais pela Igreja: Novas Formas de Diálogo com o Fiel. Gláuks, v.15, n.1, p.71-86, 2015. 
MENDONÇA, Henriete Cabral. O Catolicismo midiático: a evangelização do Padre Fábio de Melo. Dissertação de Mestrado - Sociologia. Programa de Pós-Graduação em Sociologia, Universidade Federal de Sergipe, São Cristóvão, 2013.

MIKLOS, Jorge. Ciber-religião: a construção de vínculos religiosos no ciberespaço. São Paulo: Ideias \& Letras, 2012.

NASCIMENTO, Robéria Nádia Araújo; GARCIA JUNIOR, Emilson Ferreira. Unidade na diversidade: o templo eletrônico como canal de difusão ecumênica. Revista Temática, Ano IX, n. 9, s.p., 2013.

NÓBREGA, Adilson Rodrigues da. Fábio de Melo, entre palco e altar: a imprensa brasileira e um novo olimpiano católico. In: XXXII CONGRESSO BRASILEIRO DE CIÊNCIAS DA COMUNICAÇÃO. Anais..., Curitiba, 2009, p. 1-15.

PATRIOTA, Karla Regina Macêna Pereira. Mídia e Entretenimento: em busca da religiosa audiência. REVER, Ano 8, p.1-10, 2008.

Um show destinado às massas: uma reflexão sobre o entretenimento religioso na esfera midiática. TOMO, n.14, p.181-202, 2009.

SANTOS, Suzy dos; CAPPARELLI, Sérgio. Crescei e multiplicai-vos: a explosão religiosa na televisão brasileira. Intertexto, v. 2, n. 11, p. 1-24, 2004.

SIBÍLIA, Paula. O show do eu: a intimidade como espetáculo. Rio de Janeiro: Nova Fronteira, 2008.

SILVA, Rosimeire Gonçalves da. Aspectos estéticos da figura do padre Marcelo Mendonça Rossi como contribuição para a sua imagem na fabricação de valor no imaginário social. Estética, n. 11, p.1-14, ago./dez. 2015.

SOUZA, André Ricardo de. A renovação popularizadora católica. Plural, n. 9, p. 89$101,2002$.

Igreja Católica e mercados: a ambivalência entre a solidariedade e a competição. Religião e Sociedade, v. 27, n. 1, p. 156-174, 2007.

TEIXEIRA, Faustino. Teologia e Pluralismo Religioso. São Bernardo do Campo: Nhanduti Editora, 2012. 